\title{
Synthesis and analysis of separation processes for extracellular chemicals generated from microbial conversions
}

\author{
Wenzhao $\mathrm{Wu}^{1+}$, Kirti M Yenkie ${ }^{1,2^{*}}$ (D) and Christos T. Maravelias ${ }^{1}$
}

\begin{abstract}
Recent advances in metabolic engineering have enabled the production of chemicals via bio-conversion using microbes. However, downstream separation accounts for $60-80 \%$ of the total production cost in many cases. Previous work on microbial production of extracellular chemicals has been mainly restricted to microbiology, biochemistry, metabolomics, or techno-economic analysis for specific product examples such as succinic acid, xanthan gum, lycopene, etc. In these studies, microbial production and separation technologies were selected apriori without considering any competing alternatives. However, technology selection in downstream separation and purification processes can have a major impact on the overall costs, product recovery, and purity. To this end, we apply a superstructure optimization based framework that enables the identification of critical technologies and their associated parameters in the synthesis and analysis of separation processes for extracellular chemicals generated from microbial conversions. We divide extracellular chemicals into three categories based on their physical properties, such as water solubility, physical state, relative density, volatility, etc. We analyze three major extracellular product categories (insoluble light, insoluble heavy and soluble) in detail and provide suggestions for additional product categories through extension of our analysis framework. The proposed analysis and results provide significant insights for technology selection and enable streamlined decision making when faced with any microbial product that is released extracellularly. The parameter variability analysis for the product as well as the associated technologies and comparison with novel alternatives is a key feature which forms the basis for designing better bioseparation strategies that have potential for commercial scalability and can compete with traditional chemical production methods.
\end{abstract}

Keywords: Process systems engineering, Downstream separation, Superstructure optimization, Technology selection, Bio-based chemicals

\section{Background}

Recent advances in metabolic engineering enable the use of microbes for the production of chemicals (referred to as "products" hereafter) from sugars, made from traditional sources like sugar beet and sugarcane or from alternative sources like cellulosic biomass [1-9]. Many of these chemicals are currently derived mainly from fossil

\footnotetext{
* Correspondence: yenkie@rowan.edu

${ }^{+}$Wenzhao Wu and Kirti Yenkie contributed equally to this work

${ }^{1}$ Dept. of Chemical and Biological Engineering and DOE Great Lakes

Bioenergy Research Center, University of Wisconsin-Madison, Madison, WI

53706, USA

${ }^{2}$ Department of Chemical Engineering, Henry M. Rowan College of

Engineering, Rowan University, 201 Mullica Hill Road, Glassboro, NJ 08028, USA
}

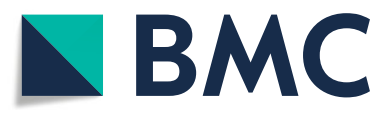

(c) The Author(s). 2019 Open Access This article is distributed under the terms of the Creative Commons Attribution 4.0 International License (http://creativecommons.org/licenses/by/4.0/), which permits unrestricted use, distribution, and

reproduction in any medium, provided you give appropriate credit to the original author(s) and the source, provide a link to the Creative Commons license, and indicate if changes were made. The Creative Commons Public Domain Dedication waiver (http://creativecommons.org/publicdomain/zero/1.0/) applies to the data made available in this article, unless otherwise stated. processes can be advantageous for their mild production conditions and direct conversion instead of step-wise chemical conversions (some steps can have low yield and high cost) [10]. Also, metabolic engineering and bioreactor engineering tools can be used to maximize the yield and selectivity of the desired product and thus minimize the concentrations of coproducts [11-16].

A bioreactor effluent is often dilute (less than $20 \mathrm{wt} \%$ product) [17] and the purity requirement for chemicals is relatively high. Therefore, downstream separation tends to be expensive, accounting for $60-80 \%$ of the total production cost in many cases $[10,18,19]$. Thus, the synthesis of an effective downstream bio-separation 
process is a critical but at the same time challenging task because multiple technologies are usually available for a given separation task, and thus a large number of alternative process networks exists. Also, the product properties and the bioreactor effluent compositions are not uniform across chemicals, but rather specific, which requires case-specific considerations.

Methods used for process synthesis generally include an enumeration of alternatives, evolutionary modification, and superstructure optimization [20, 21]. In the enumeration of alternatives, each alternative design is generated and evaluated. In an evolutionary modification, designers make changes to known flowsheets for similar processes to meet new objectives and constraints. An optimization model can also be formulated to facilitate the comparison between different flowsheets and determination of process variables such as flowrates, operating temperatures, and pressures [22-27]. However, these two methods are not feasible for cases where a large number of different technologies is available for comparison. On the other hand, a superstructure optimization is a model-based approach that compares alternative process networks simultaneously [28-30].

In some cases, the generation of schemes can assist in the generation of superstructures for the synthesis of separation networks [24, 31-37]. A scheme incorporates a list of technologies available for a set of tasks, while a superstructure incorporates a number of alternative specific technologies and relevant interconnections. Superstructure optimization has been proposed for the synthesis of separation networks $[20,38-42]$ as well as the development of bio-processes [33, 39, 43-49]. However, these studies were mostly focused on either general methodological discussions or analysis for specific products on a case-by-case basis. The recent studies by Maravelias group $[42,50,51]$ have presented a systematic approach for generating and modeling bio-separation superstructures for different classes of products defined in terms of a set of attributes including product localization, solubility, density, volatility, physical state, and intended use. This work builds on those recent studies to look at microbial products released extracellularly in more detail through carefully selected case studies, appropriate parameter values, typical range of variation and additional insights derived from solving multiple optimization problems.

When a product of interest is produced by microbial cells, it is then localized either inside the cells or released to the extracellular phase. In fact, most products are initially produced intracellularly, but some products are localized extracellularly to the aqueous medium through passive diffusion or active transport [52]. Previous work on economic assessment for the separation of extracellular chemicals has been mainly restricted to specific examples such as hyaluronic acid [53-57], limonene
[58-61], xanthan gum [62, 63], butanediol [64-67], lactic acid [68-72] and penicillin V [19, 73, 74]. Also, assessment studies have been performed for individual separation technologies [75-77]. However, technology selection is nontrivial because many competing alternatives are often available and when considered in a complete separation network for cost minimization, it adds to further complexity as optimal solutions become non-intuitive. Moreover, traditional analyses have usually focused on sensitivity analyses for separation networks with fixed technologies, and single parameter variation at a time to assess its influence on the process economics $[78,79]$.

In this work, we synthesize and analyze separation processes for extracellular products, aiming to convert a dilute effluent (containing product, microbial cells, water, and small amounts of co-product impurities) from a microbial-based reactor to a high-purity product stream. The synthesis aspect has been addressed in more details in Yenkie et al. [50], however, the aspects relevant to the superstructure synthesis for separation of extracellular products in also presented in Fig. 1a and b and have been revisited wherever possible. However, the paper focuses on deriving critical insights from the detailed cost and technological parameter variation analysis for the extracellular products. Extracellular products have many distinguishing features, especially they can be present in very low concentrations in water abundant process streams. Moreover, some tasks such as cell disruption are not needed for extracellular products. Thus, extracellular product classes are treated separately and the critical insights derived in this work can provide better downstream separation and purification design strategies for these products and can also provide future research directions for technology enhancement. Note that we only consider liquid or solid products entering the separation networks.

In the "Methods" section, we discuss a stage-wise separation scheme, superstructure generation and modeling, and the analysis framework we employ. In the "Results and discussions" section, we first categorize extracellular products into three different categories based on their physical properties: (1) insoluble light (with a density lower than that of water), (2) insoluble heavy, and (3) soluble. Such categorization is necessary because, e.g., separation of extracellular insoluble light products tends to be easier (via simple decantation, filtration, etc.) than that of extracellular soluble ones (via distillation, membrane, precipitation, etc.), especially when the product titer is low. Second, in each category, we develop a base case, to generate the cost-minimal process with the optimal technology selection and identify the key cost drivers. Third, we analyze the influence of these drivers (such as product titer and technology performances) on 

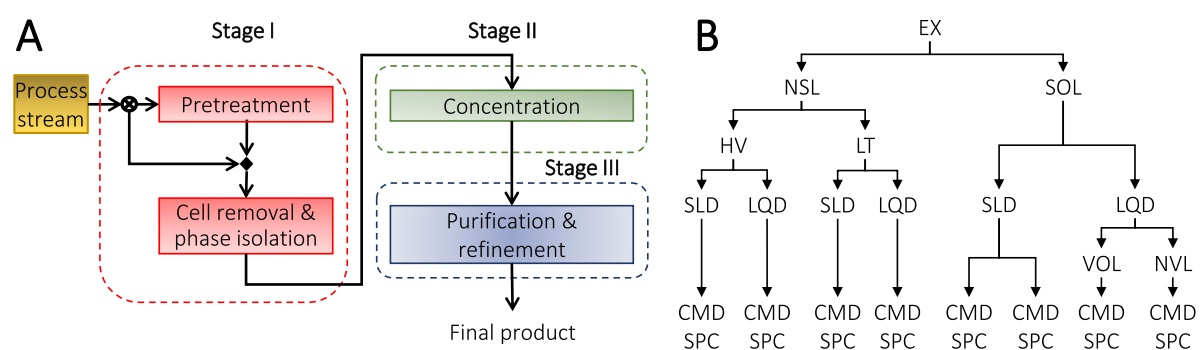

Fig. 1 Stage-wise separation scheme and its simplification. a Representation of the three-stage separation scheme for extracellular products; $\mathbf{b}$ simplification of the separation scheme for superstructure generation based on product properties (solubility, density, physical state, volatility and intended use). Abbreviations: solubility in water [insoluble (NSL) or soluble (SOL)], density with respect to water [heavy (HV) or light (LT)], physical state [solid (SLD) or liquid (LQD)], relative volatility with respect to water [volatile (VOL) and non-volatile (NVL)], and intended use [commodity (CMD) or specialty (SPC)]

optimal technology selection and cost. Finally, we extend the discussion to account for other classes of products in the category.

\section{Methods}

\section{Stage-wise separation scheme}

The recovery of an extracellular (EX) product is divided into three stages: (I) Product isolation (including pretreatment, cell removal, and phase isolation), (II) Product concentration, and (III) Product purification and refinement, as shown in Fig. 1a. These three stages have been formulated after careful consideration of previous literature and reports on bioseparations and downstream processing by Belter, Cussler and $\mathrm{Hu}$ [31], Harrison [32, 80], Chisti [81-85], Asenjo [16, 22, 27, 86, 87], and Bogle [39, 88, 89]. Each stage has multiple technologies available for every task, as shown in Table 1.

We will use the abbreviations when referring to the specific technologies hereafter. For discussions regarding the three stage scheme and the specific separation technologies, the readers are referred to [42, 50, 51]. We would like to point out that we have chosen the most basic configurations for the technology models. For example, filtration and membrane processes can have varied designs such as depth filtration, diafiltration, cascaded designs [90-92], etc. However, these varied configurations will not change the broader insights and typical cost ranges obtained from this work.

\section{Extracellular product classes}

The potential separation stages and the relevant technology options in the separation scheme (see Fig. 1a and Table 1) can be narrowed down based on other distinguishing properties of an extracellular (EX) product such as the solubility of the product in water [insoluble (NSL) or soluble $(\mathrm{SOL})$ ], density with respect to water [heavy (HV) or light (LT)], physical state [solid (SLD) or liquid (LQD)], relative volatility with respect to water [volatile (VOL) and non-volatile (NVL)], and intended use [commodity (CMD) or specialty (SPC)], as shown in Fig. $1 \mathrm{~b}$. Each combination of these properties corresponds to a specific class of products, e.g., 2,3-butanediol belongs to the EX SOL NVL LQD CMD class.

\section{Superstructure generation and modeling}

For each class of extracellular products, we generate a superstructure that is based on the rules and information presented in the prior work on separation network synthesis [42, 50] and has also been revisited briefly in Fig. 1a and b. Next, we formulate a superstructure optimization model in the form of mixed-integer nonlinear programming (MINLP) problem, with binary

Table 1 Technology options available for performing the tasks listed in the three separation stages. Abbreviations for the technologies are shown in parentheses

\begin{tabular}{|c|c|}
\hline Tasks & Technologies \\
\hline Pretreatment & Flocculation (Flc) \\
\hline $\begin{array}{l}\text { Cell removal and product } \\
\text { isolation }\end{array}$ & $\begin{array}{l}\text { Sedimentation (Sdm), filtration (Ftt), centrifugation (Cnt), flotation (Flt), membranes (Mbr- MF [microfiltration], UF } \\
\text { [ultrafiltration], and RO [reverse osmosis]) }\end{array}$ \\
\hline $\begin{array}{l}\text { Phase isolation } \\
\text { (product rich phase formation) }\end{array}$ & Differential digestion (Ddg), solubilization (SIb) \\
\hline Concentration & $\begin{array}{l}\text { Extraction (Ext), aqueous two phase extraction (Atpe), evaporation (Evp), precipitation (Prc), sedimentation (Sdm), } \\
\text { filtration (Ftt), centrifugation (Cnt), membranes (MF, UF, NF (nanofiltration), RO), distillation (Dst) }\end{array}$ \\
\hline Purification \& refinement & $\begin{array}{l}\text { Adsorption (Ads), chromatography (Chr), crystallization (Crs), pervaporation (Pvp), membranes (Mbr-MF, UF, NF, RO), } \\
\text { Drying (Dry), bleaching (Blc) }\end{array}$ \\
\hline
\end{tabular}


variables denoting the activation/deactivation of technologies present in the superstructure. The model involves constraints describing the separation technologies, stream flows, input specifications, and product purity requirements. The typical number of equations involved in an extracellular product case study can range from $\sim 600-1700$, model variables can range from $\sim 500-1200$ with $\sim 25-35$ discrete variables depending on the number of tasks and technology alternatives involved in the complete superstructure. The objective is to minimize the total cost, including annualized capital cost and operating cost (input feedstock, consumables, labor, utility, materials, etc.) [21, 93]. We assume reasonable base case values for the process, technology and economic parameters such as product titer, technology efficiencies, and material costs (refer Table 2). The specific model equations for each technology (material and energy balances, design and costing equations) and the parameter values used in the current work can be found in the Additional file. The model has been developed in GAMS 25.1.1 environment and solved using BARON [94, 95], a global optimization solver.

\section{Analysis framework}

For each product category, after solving the base case to determine the cost-minimal separation network and the key cost drivers, we further analyze how variations in the key drivers affect the cost and technology selection, in two steps:

Step\#1: Vary one or a combination of key parameters and solve an optimization problem for each combination, to determine the threshold values where a change in the optimal technology happens.

Step\#2: Extend the analysis to other product classes in the category based on (1) the results for the base case, if the same technology options are suitable for the other classes, or (2) individual technology considerations, if new technologies should be included.

\section{Results and discussions}

Study1 - extracellular insoluble light (EX NSL LT) products For the EX NSL LT category, we choose an EX NSL LT LQD CMD product as the representative base case. Note that EX NSL LT products float on the top and are thus naturally separated from the dense microbial cells. The key parameters used are shown in Table 2 . The base case parameters have been chosen to represent typical cases reported in the literature for products belonging to EX NSL LT class such as terpenes $[58,59,96]$. The analysis range for the product titer has been chosen up to $250 \mathrm{~g} / \mathrm{L}$ to reflect the possibilities of achieving higher product concentrations due to advances in metabolic engineering and bioreactor designs [97-99].

\section{Superstructure and optimal solution}

By simplifying the separation scheme of an EX NSL product (provided in Additional file 1: Figure S. A1), we obtain the superstructure for EX NSL LT LQD CMD product shown in Fig. 2. In Stage I - phase isolation, Sdm1 (sedimentation), and Cnt1 (centrifugation) separate the product as a top phase (isolated from the cells at the bottom) while removing water at the same time. Ftt (filtration) functions to only remove the cells. In Stage II concentration, Sdm2, Cnt2 and Mbr (membranes) can separate the product from water, which can be bypassed if enough concentration has been achieved in Stage I. In Stage III - refinement, Ads (adsorption) further purifies the product, which can also be bypassed if the optimization model decides that the final product specifications have been satisfied. The optimization model comprises 601 equations, 486 continuous variables and 33 discrete variables and takes about a minute or two to solve for one set of parameter values.

After solving the superstructure optimization model, we obtain the cost-minimal separation network (Cnt1 in Stage I followed by Cnt2 in Stage II), as represented by the highlighted parts in Fig. 2, as well as the corresponding cost distribution. The total minimum cost is $0.65 \$ / \mathrm{kg}$, with the feed accounting for $60 \%$ of the total cost, Stage I

Table 2 Key parameters for the base case and further analysis for EX NSL LT LQD CMD product

\begin{tabular}{|c|c|c|c|}
\hline Parameter category & Parameter & Base case (nominal) & Range \\
\hline \multirow[t]{2}{*}{ Operation choices } & Production capacity (kg/h) & 1000 & - \\
\hline & Annual operation time (days) & 330 & - \\
\hline \multirow[t]{3}{*}{ Product streams } & Initial product titer (g/L) & 5 & $1-250$ \\
\hline & Initial microbial cells (g/L) & 2 & - \\
\hline & Final product purity (wt\%) & 95 & - \\
\hline \multirow[t]{4}{*}{ Separation technologies } & Sdm efficiency & $70 \%$ & - \\
\hline & Cnt efficiency & $80 \%$ & $70-95 \%$ \\
\hline & Ftt retention factor & $80 \%$ & $70-95 \%$ \\
\hline & Mbr rejection coefficient & $97 \%$ & - \\
\hline
\end{tabular}




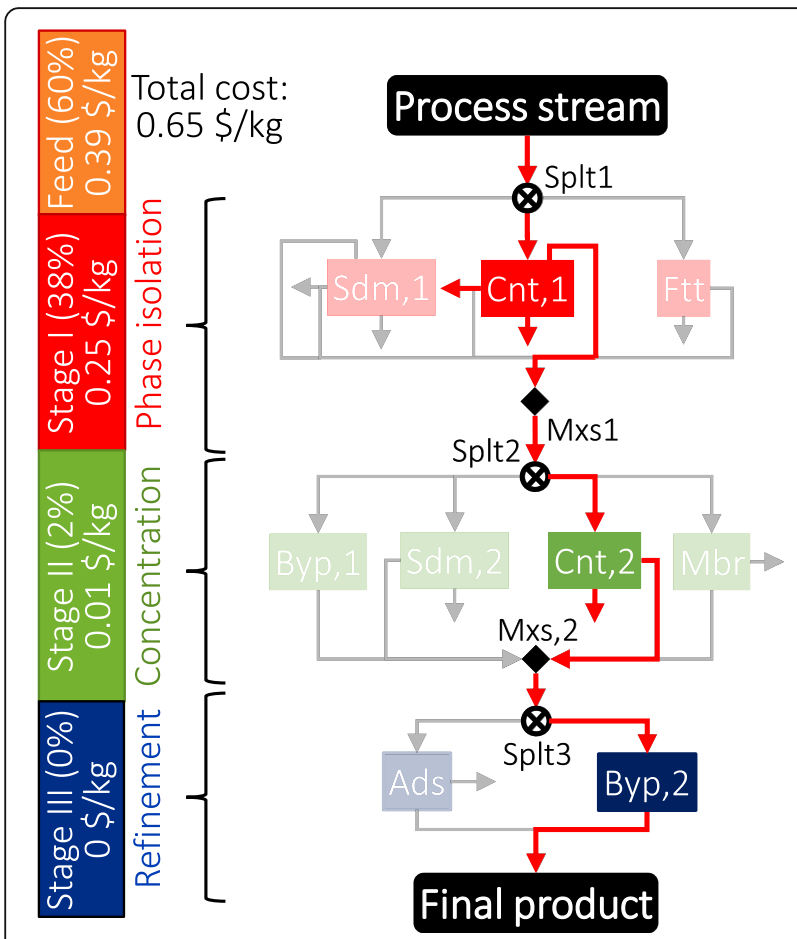

Fig. 2 Superstructure with all technologies and streams and highlighted optimal solution for EX NSL LT LQD CMD product. The active streams are shown by bold red lines and selected technologies are highlighted in different colors corresponding to each stage: red for stage I, green for stage II, blue for stage III and Byp for bypassing a stage. Cost distribution is shown by the numbers on the left bar

accounting for $38 \%$, and Stages II for $2 \%$ of the total costs. Cnt2 is also selected because Cnt1 alone is not able to concentrate the product stream from $5 \mathrm{~g} / \mathrm{L}(\sim 0.5 \mathrm{wt} \%)$ to the required final purity of $95 \mathrm{wt} \%$ due to concentrating factor limitations (see centrifugation (Cnt) parameters in Additional File).

\section{Analysis for EX NSL LT LQD CMD product}

Performance of phase isolation technologies Since the major cost component in the optimal network is Stage I, we vary parameters related to the phase isolation technologies: sedimentation $(\mathrm{Sdm})$, centrifugation $(\mathrm{Cnt})$ and filtration (Ftt). The performance for Sdm1 and Cnt1 is defined in terms of "efficiency" of the separation of product from the aqueous phase. For Ftt, it is defined as the retention factor of cells on the retentate side of the filter. We vary the Cnt1 efficiency and Ftt retention factor between 70 and $95 \%$ simultaneously $[81,85,100,101]$ and run the optimization model to obtain the optimal separation network and cost for each combination of these two parameters. This analysis requires the solution of about 150-200 optimization problems to generate the complete heatmap shown in Fig. 3. Note that for the efficiency of

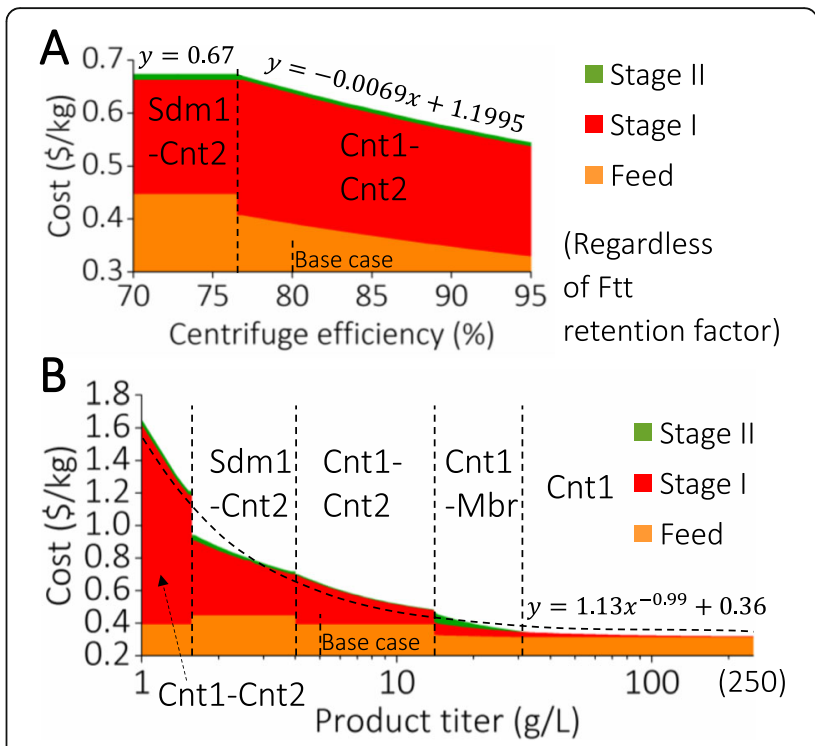

Fig. 3 Analysis on technology selection and cost variation for EX NSL LT LQD CMD product. a Analysis with varying Cnt1 efficiency and Ftt retention factor; $\mathbf{b}$ analysis with varying product titer. The optimal technologies selected are labeled in the corresponding regions. The fitted functions are shown, where $y$-axis represents the cost, and $x$-axis represents the Cnt1 efficiency and product titer in (a) and (b), respectively. The base cases are marked with short dashed lines with "Base case" labels next to them

$\mathrm{Sdm} 1$, there is limited scope for performance enhancement [81], therefore, we fix it to $70 \%$.

As a result, regardless of the Ftt retention factor variation, Ftt is not selected in the optimal solution (see Fig. 3a). This is because Ftt can only separate the cells from the product and water, while Cnt1 or Sdm1 functions to remove water at the same time. The optimal technologies selected are noted in the corresponding regions in Fig. 3a. The readers can identify the optimal separation network in Fig. 2 accordingly. The same notation is used in the subsequent figures. It can be seen, when the Cnt1 efficiency is below $76.5 \%$, Sdm1 is selected in Stage I, and Cnt2 is selected in Stage II due to lower cost; otherwise, Cnt1 and Cnt2 is selected. Since the efficiency of Cnt2 is still fixed to $80 \%$, Cnt2 is always selected as the optimal technology in Stage II.

Product titer $\mathrm{Sdm} 1$ and $C$ nt1 equipment sizes are the major phase isolation cost drivers, and they depend on the product titer in the feed entering the separation network (affecting the total input stream flow rate). Product titer depends on the microbial strain, substrate utilization, microbial-conversion pathways, and bioreactor design. It has the potential to be altered by metabolic engineering tools $[17,102-105]$. We vary the product titer from 1 to $250 \mathrm{~g} / \mathrm{L}$ and obtain the costs and the corresponding optimal technology selection in Fig. 3b. 
It can be seen that at high titer $(\geq 32 \mathrm{~g} / \mathrm{L})$, Cnt1 alone is able to achieve the required product purity. When the titer is $14-32 \mathrm{~g} / \mathrm{L}$, another concentration technology is required in Stage II, and $\mathrm{Mbr}$ is preferred to $\mathrm{Sdm} 2$ and Cnt2 because the product loss is lower. When the titer is $4-14 \mathrm{~g} / \mathrm{L}$, Cnt2 becomes a better option than Mbr in Stage II because the low titer requires large Mbr equipment size and more costs associated with Mbr replacements. When the titer is $1.57-4 \mathrm{~g} / \mathrm{L}, \mathrm{Sdm} 1$ is a cheaper option than Cnt1 in Stage I because the major cost of $\mathrm{Sdm}$ is equipment cost, which is scaled with the equipment size based on the power scaling rule; however, in addition to equipment cost, Cnt also has electricity cost, which is scaled linearly with the equipment size. Therefore, when the titer is low (leading to large equipment size), Cnt1 electricity cost is high, and thus $\operatorname{Sdm} 1$ is a cheaper option. Finally, when the titer is $<1.57 \mathrm{~g} / \mathrm{L}, \mathrm{Sdm} 1$ in Stage I is limited by its maximum concentrating factor and thus is not able to concentrate the product enough for Stage II to reach the required purity. Therefore, Cnt1, with a higher concentrating factor, is selected.

\section{Extension to other classes of EX NSL LT products}

The other properties determining the superstructure for EX NSL LT products are the physical state (LQD/SLD) and intended use (CMD/SPC) (see Fig. 1b). The SPC (specialty) products have a high purity requirement, thus require additional treatment technologies which make their recovery more expensive in comparison to commodity products.

For a SLD product, Ftt in Stage I cannot separate the product from the cells, and thus it should be removed from the superstructure. However, since Ftt is not selected in the optimal network, our base case analysis is still able to reflect the potential technologies and the overall separation network for SLD product.

For an SPC product, separation technologies in Stage III need to be more stringent to meet the purity requirements. Thus, technologies such as Chr (chromatography) and Blc (bleaching - to remove pigments) can be included in the superstructure, and a similar analysis can be performed to identify the impact of variation in technology parameters in Stage III. However, the Stage III parameters are not selected for further analysis because, for highvalue specialty chemicals, quality is a major concern and cost minimization becomes secondary [106].

\section{Study2 - extracellular insoluble heavy (EX NSL HV) products}

For this category, we choose EX NSL HV SLD CMD product as a representative base case. The key parameters used are the same with those in the EX NSL LT base case (refer Table 2). Other parameters can be found in the Additional file. Some representative products belonging to the EX NSL HV class are hyaluronic acid [54-56], and xanthan gum [62, 63].

\section{Superstructure and optimal solution}

By simplifying the separation scheme of an EX NSL product (see Additional file 1: Figure S.A1), we obtain the superstructure for EX NSL HV SLD CMD product, as shown in Fig. 4. Since the product is extracellular (EX), Stage I consists of phase isolation and cell removal. Phase isolation (i.e., the separation of the productcontaining phase from other components in the stream), can be achieved using Slb (solubilization) or Ddg (differential digestion). Slb is used to dissolve the product in a suitable solvent to separate it from cells and other solid impurities. Ddg is used to dissolve the Non-Product Containing Materials (NPCM). Cell removal technologies include Sdm, Cnt, Ftt, and Mbr. Multiple technologies may be required in series depending on the initial product and cell concentration in the inlet stream. Flc (flocculation), as an optional pretreatment technology, can enhance the separation efficiency of subsequent tasks by enabling the formation of flocs of cells, which are then easier to isolate from the aqueous phase.

Stage II is required if the process stream undergoes solubilization (Slb) in Stage I. Stage II includes precipitation (Prc) followed by the phase separation technologies which are similar to the ones used for cell removal. If Ddg is selected in Stage I, then Stage II is not required. Stage III involves bleaching (Blc) and drying (Dry) options for final product purification.

The optimization model comprises 1618 equations, 1137 continuous variables and 30 discrete variables and takes about a minute or two to solve to optimality for one set of parameter values. The solution of the superstructure optimization model yields the cost-minimal separation network, as represented by the highlighted parts in Fig. 4, as well as the corresponding cost distribution shown on the left bar alongside the superstructure. The technologies selected in Stage I are Ddg (differential digestion) for phase isolation and Cnt3 (centrifugation) and Cnt4 for cell removal. The final product refinement involves Blc (bleaching) to remove undesired color imparting impurities and Dry (drying) to retrieve product in the solid form. The overall process cost is $4.20 \$ / \mathrm{kg}$, where the separation cost contribution is $\$ 3.81 / \mathrm{kg}(91 \%)$. Stage I is the highest cost contributor (51\%).

\section{Analysis for EX NSL HV SLD CMD product}

Performance of phase isolation and cell removal technologies Since Ddg is used for phase isolation, Stage I is the major cost contributor in the optimal configuration, $41 \%$ of the overall cost). Its competing 


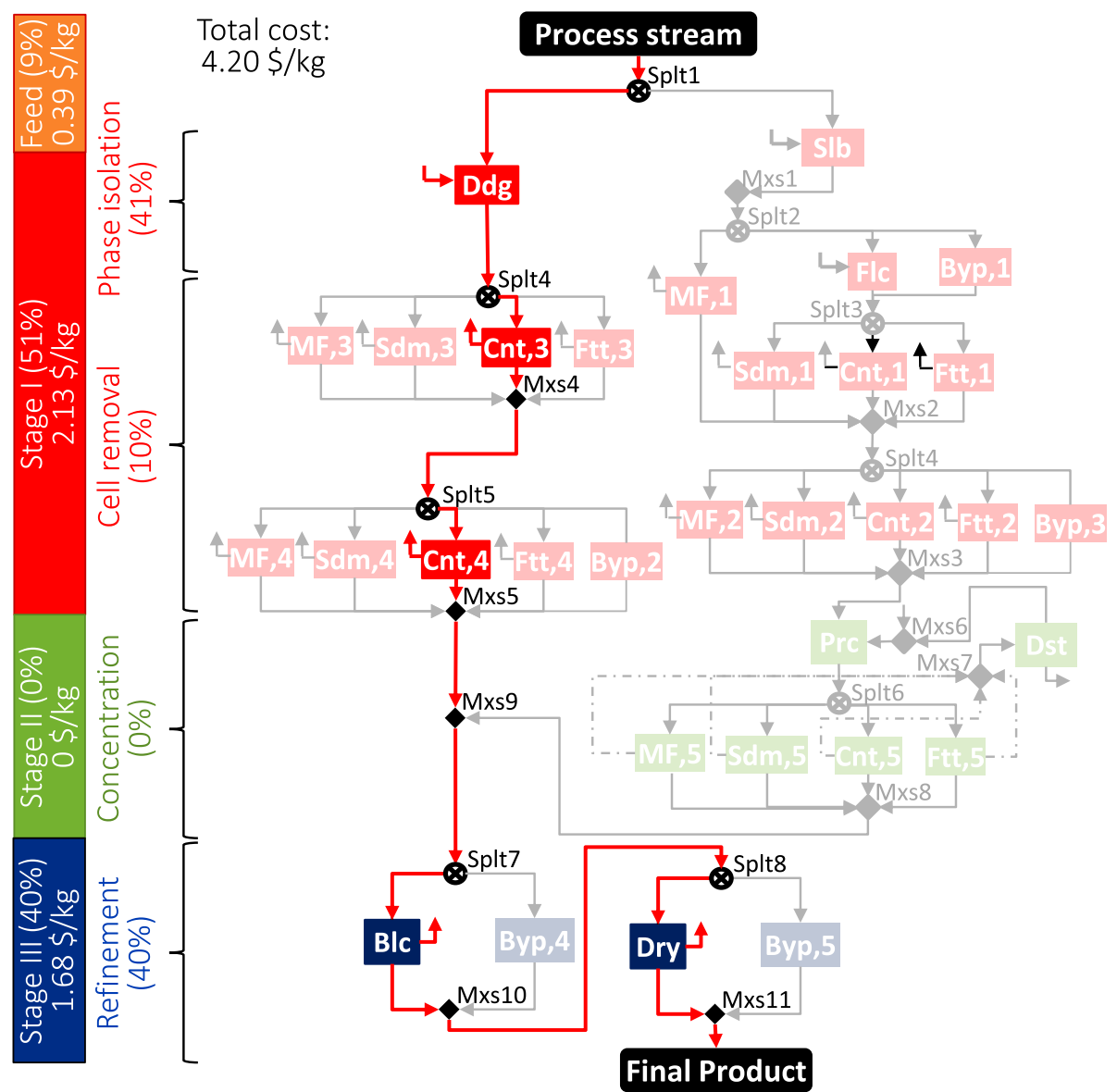

Fig. 4 Superstructure with all technologies and streams and highlighted optimal solution for EX NSL HV SLD CMD product. The active streams are shown by bold red lines and selected technologies are highlighted in different colors corresponding to each stage: red for stage I, green for stage II, and blue for stage III. Cost distribution is shown by the numbers on the left bar

technology is Slb, hence, we vary the required amount of the NPCM digestion agent and the solubilizing solvent, as shown in Fig. 5a. Ddg is the preferred option even if the digestion agent is required in higher amounts as compared to Slb solvent. This is because Slb selection adds additional cost in Stage II, where Prc (precipitation) followed by phase separation is required.

The second major cost component is Blc ( $28 \%$ of the overall cost). However, there is limited room for performance improvements since the Blc efficiency is typically high $\sim 99 \%$. This is reasonable as Blc is a Stage III technology which already has the input stream with the product in concentrated form with traces of colorimparting impurities.

The next major cost component is Cnt3 (8.4\% of the overall cost) for cell removal, and its performance affects product loss and Stage III cost. Therefore, we also vary the Cnt3 efficiency and Ftt3 retention factor between 70 and $95 \%$ simultaneously, while fixing $\mathrm{Sdm} 3$ efficiency to $70 \%$, for the same reason discussed in the previous case study for EX NSL LT products. The analysis is shown in
Fig. 5b. Cnt3 is the preferred option in most cases because its capital cost is lower than that of $\mathrm{Sdm} 3$, and Ftt3 filter replacement costs are high.

Product titer We vary the product titer from 1 to 250 $\mathrm{g} / \mathrm{L}$. The costs and the corresponding optimal technology selection are obtained and presented in Fig. 5c. We observe that when the titer is greater than $52 \mathrm{~g} / \mathrm{L}$, DdgCnt3-Dry (differential digestion-centrifugation-drying) is the optimal selection; from 15 to $52 \mathrm{~g} / \mathrm{L}$, further concentration by Cnt4 (centrifuge) is needed to achieve the final purity requirement; from 2.2 to $15 \mathrm{~g} / \mathrm{L}$, the amount of color imparting impurities is substantial compared with the amount of product present, and thus Blc (bleaching) is required; when the titer is less than $2.2 \mathrm{~g} /$ L, MF4 (microfiltration) replaces Cnt4 due to limitations of Cnt4 concentrating factor. Note that we have assumed that color imparting impurities exist and thus Blc is required in some cases. To account for cases where no such impurities exist (and thus Blc is not necessary), we also present the corresponding cost-titer curve in 


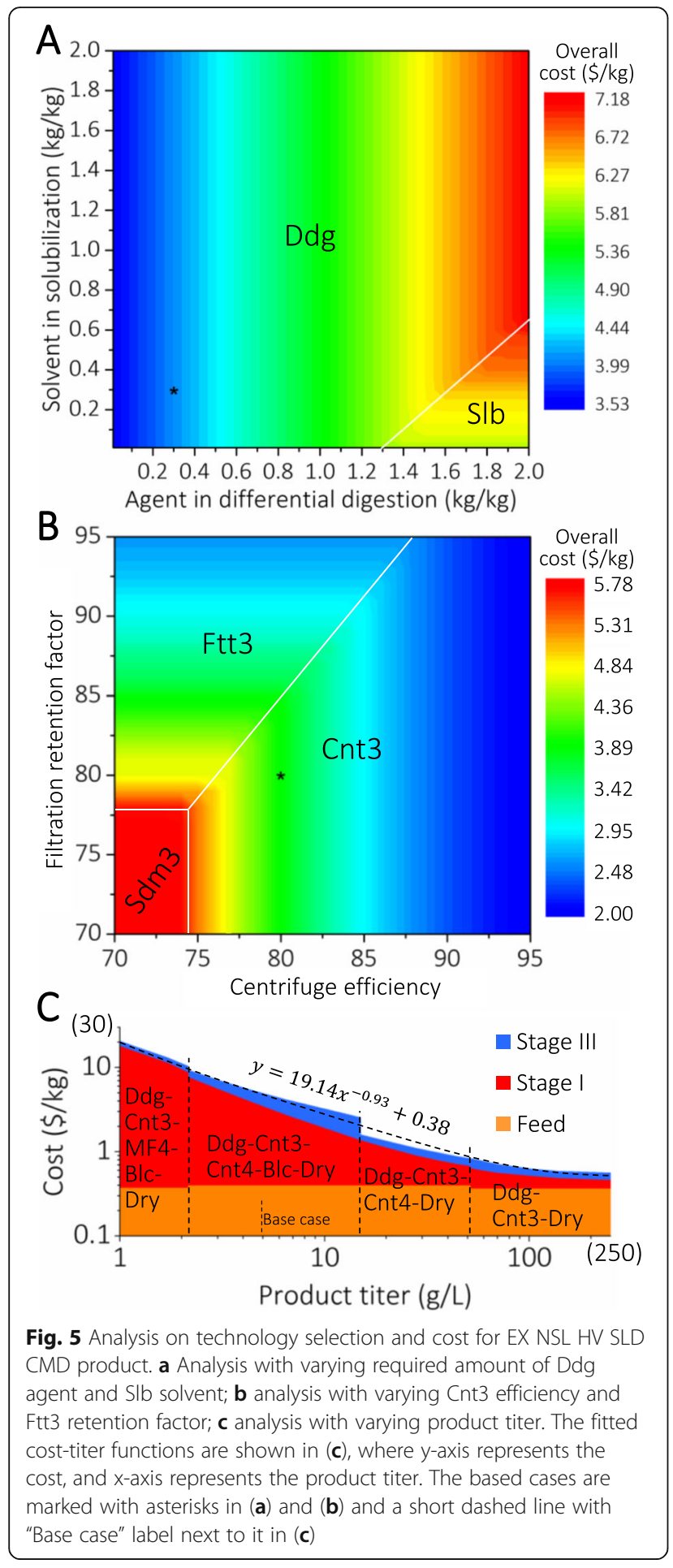

Additional file 1: Figure S.A2. Sometimes larger product titers for NSL products at high temperatures can lead to viscous process streams. However, in our technology models, we have accounted for heat dissipation effects in a centrifuge and considered appropriate cooling utility to maintain the normal operating temperatures.

\section{Extension to other classes of EX NSL HV products}

The other properties determining the superstructure for EX NSL HV products are the physical state (LQD/SLD) and intended use (CMD/SPC) (see Fig. 1b). For a LQD product, instead of using Ddg or Slb (see Fig. 4), Ftt or Mbr (depending on the size of solid impurities) can be used directly to separate the product from cells, followed by concentration using Sdm, Cnt or Mbr. Also, Dry in Stage III is only applicable to SLD products and thus should be removed. Therefore, for LQD product, the separation cost will be lower. We modify the base case superstructure to account for LQD product, and the optimal technology selections are Flc-Ftt-MF-Blc (flocculation-filtration-microfiltration-bleaching), and the cost is decreased from $4.2 \$ / \mathrm{kg}$ (for SLD) to $3.52 \$ / \mathrm{kg}$ (for LQD), as shown in Additional file 1: Figure S.A3. For a SPC product, separation technologies in Stage III need to be more stringent for high purity requirements. Similar considerations mentioned for EX NSL LT products will be valid here.

\section{Study3 - extracellular soluble (EX SOL) products}

For this category, we choose EX SOL LQD NVL CMD product as the base case. The key parameters used are the same as those in the EX NSL LT base case (refer Table 2). The remaining parameters can be found in the Additional file 1: Table S.C.B1. The typical examples for EX SOL products from microbial sources include propanediol [107, 108] and butanediol [64-67].

\section{Superstructure and optimal solution}

By simplifying the separation scheme of an EX SOL product (see Additional file 1: Figure S.B1), we obtain the superstructure for EX SOL LQD NVL CMD product, as shown in Fig. 6. In Stage I, cells are first removed, and thus the aqueous phase containing the product is isolated. Then, in Stage II, Dst (distillation), Atpe (aqueous two-phase extraction), and Ext (extraction) are considered as concentrating technologies. Finally, in Stage III, Pvp (pervaporation) can be used to remove small amount of remaining impurities, if necessary. The optimization model comprises 969 equations, 754 continuous variables and 25 discrete variables and takes about $30 \mathrm{~min}$ to $5 \mathrm{~h}$ to solve the problem to optimality for one set of parameter values. This is due to the presence of the distillation and extraction model equations which include logarithmic and exponential terms involving mole fractions of components.

After solving the superstructure model, we obtain the cost-minimal separation network represented by the highlighted parts in Fig. 6, as well as the corresponding cost distribution. The technologies selected in stage I are Flc (flocculation), Cnt1 (centrifuge), and Cnt2. Atpe, followed by MF3 (microfiltration) and MF4, is selected 


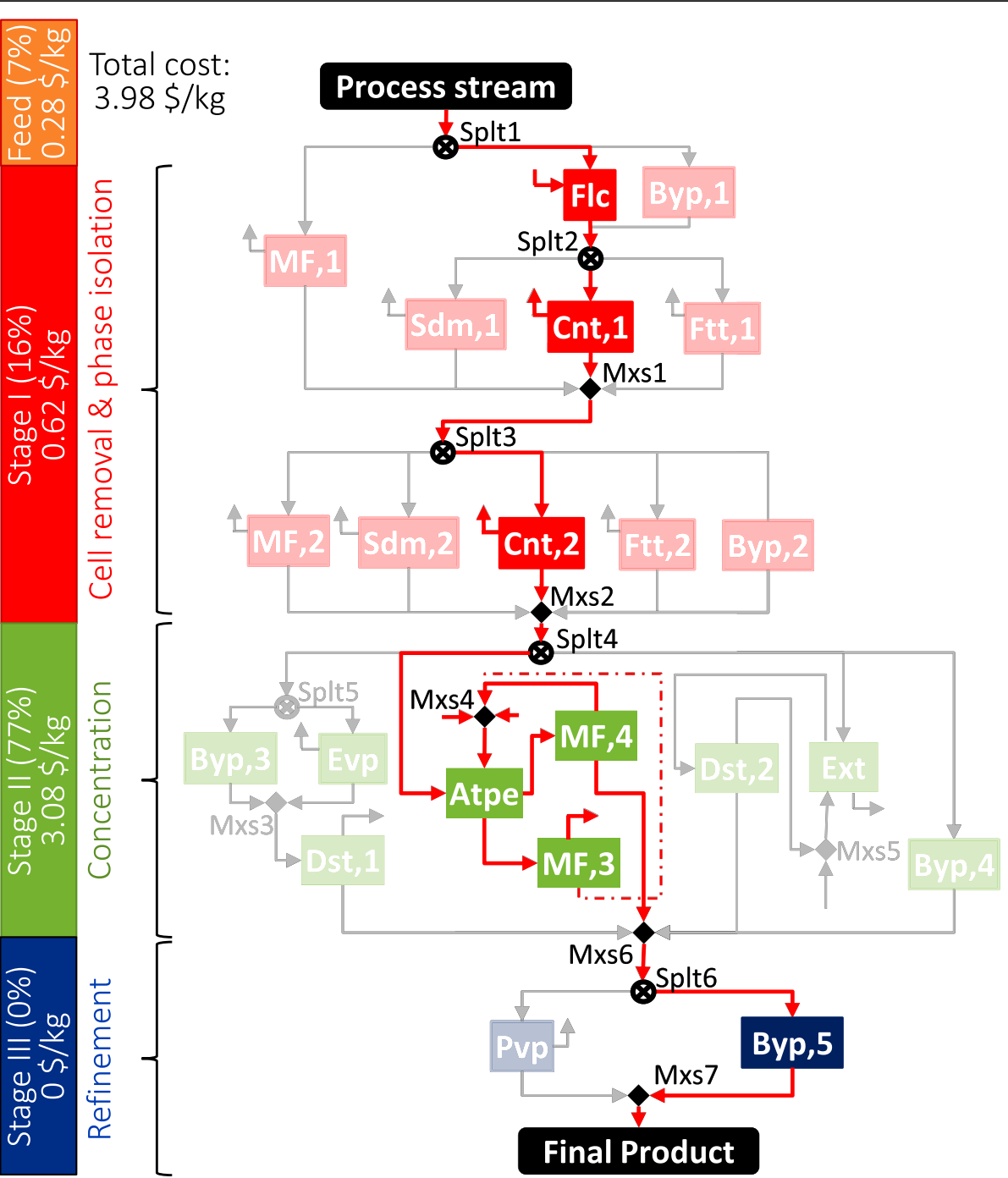

Fig. 6 Superstructure with all technologies and streams and highlighted optimal solution for EX SOL LQD NVL CMD product. The active streams are shown by bold red lines and selected technologies are highlighted in different colors corresponding to each stage: red for stage I, green for stage II, and blue for stage III. Cost distribution is shown by the numbers on the left bar

for concentration in Stage II. Stage III is bypassed. The total minimum cost is $3.98 \$ / \mathrm{kg}$, with the feed accounting for $7 \%$, Stage I $16 \%$ and Stage II $77 \%$. Stage II is the major cost component because the separation for soluble product requires concentration of the product present in water-rich phase.

\section{Alternative concentration options in stage II}

Atpe (aqueous two-phase extraction) is selected in the optimal network for the base case. However, we also analyze the separation networks when Ext (extraction) or Dst1 (distillation) is selected in Stage II, thus accounting for cases where effective Atpe using alcohol-salt [109], polymer-salt [110] or polymer-polymer [111, 112] phases for the product may not exist.
When Ext (as well as its auxiliary Dst 2) is selected (by setting the binary variable for Ext to 1 to ensure selection), the technologies selected (see Fig. 7a) in Stage I include Flc, Cnt1, and Cnt2. Stage III is bypassed. The overall process cost is $4.06 \$ / \mathrm{kg}$, and the separation cost contribution is $3.77 \$ / \mathrm{kg}(94 \%)$. Stage II is still the major cost contributor (80\%).

When Dst1 is selected, the technologies selected (see Fig. 7b) in Stage I include Flc, Cnt1, and Cnt2. Stage III is bypassed. The overall process cost is $8.19 \$ / \mathrm{kg}$, and the separation cost contribution is $7.93 \$ / \mathrm{kg}(97 \%)$. Stage II is still the major cost contributor (90\%). Direct Dst is costly because a large amount of water needs to be vaporized in Dst1, which increases the heating utility costs in the system.

We can see a major difference in the cost distribution for soluble products based on their localization. From 

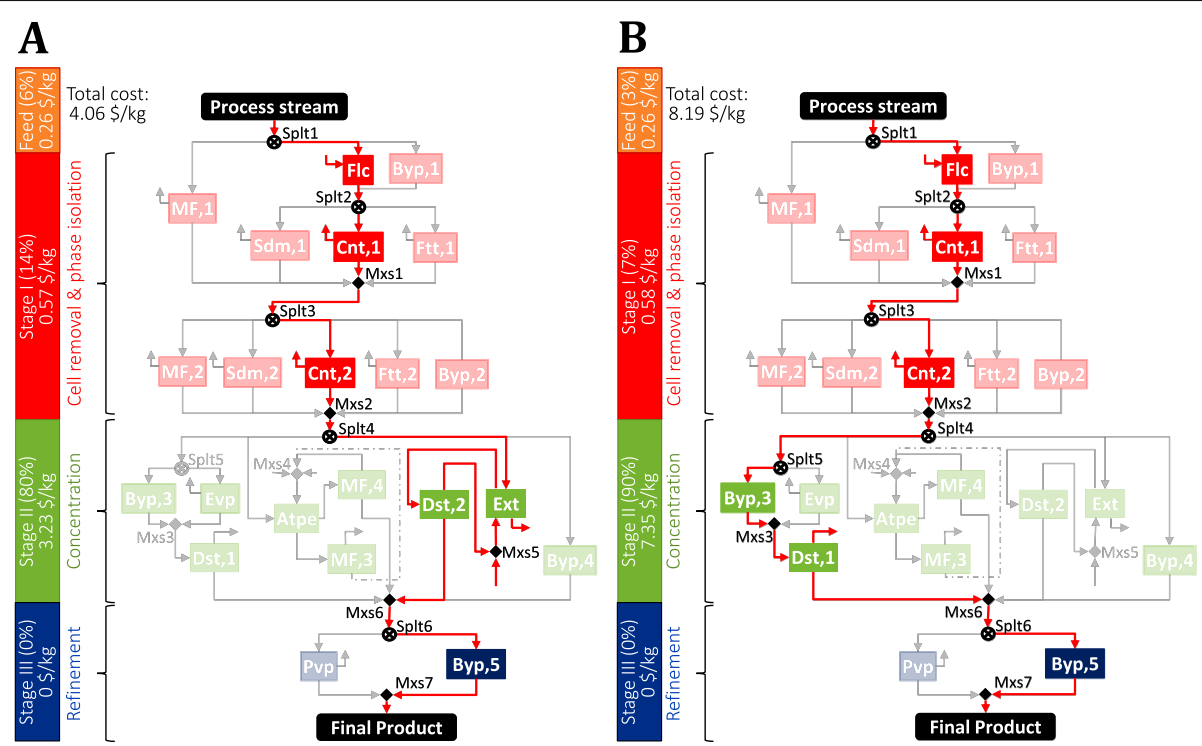

Fig. 7 Technologies selected for Extraction (Ext) and direct Distillation (Dst) options in stage II for EX SOL LQD NVL CMD product. a Technologies selected when Ext is selected; $\mathbf{b}$ technologies selected when Dst1 is selected. The active streams are shown by bold red lines and selected technologies are highlighted in different colors corresponding to each stage: red for stage I, green for stage II, and blue for stage III. Cost distribution is shown by the numbers on the left bar

the previous study on intracellular products [51], the major cost driver was Stage I irrespective of the other properties of the product, however, for extracellular products, Stage II costs take precedence and have a major impact on the overall downstream separation network selection.

\section{Analysis for EX SOL LQD NVL CMD product}

Since Stage II is the major cost driver, we perform the analysis with varying parameters related to Atpe, Ext and Dst1.

Partition coefficient for Atpe The major cost driver of Atpe is the equipment size, which is a function of the flowrates of feed and added separating agents (alcohol/ polymer for the top phase and salt for the bottom phase). The amount of agents required is affected by the partition coefficient for the top phase (KpT), which we vary from 3 to 10 while fixing Atpe selection. These are valid choices for the $\mathrm{KpT}$ values based on the literature for typical Atpe systems [66, 109]. In Fig. 8a, we observe that the overall cost decreases from $4.25 \$ / \mathrm{kg}$ to 3.63 $\$ / \mathrm{kg}$ with the increase of partition coefficient from 3 to 10 , which enables more product to be extracted into the top phase and thus reduces the amount of separating agents required. When the Atpe partition coefficient is below 3.7 (thus cost $>4.06 \$ / \mathrm{kg}$ ), Atpe becomes a more expensive option than Ext, assuming the base case parameters for Ext (see Fig. 7a).
Ext parameters -solvent solubility, cost and partition coefficient For Ext, the solvent is the major cost contributor, and thus we vary solubility of solvent in water from 0.0002 to $0.03 \mathrm{~kg} / \mathrm{kg}$ and vary the cost of solvent from 0.2 to $1.5 \$ / \mathrm{kg}$ while fixing Ext selection, and the analysis result is shown in Fig. 8b. Compared with the base case, if the solubility decreases from 0.02 to 0.0002 $\mathrm{kg} / \mathrm{kg}$ and the solvent cost decreases from 1.2 to 0.2 $\$ / \mathrm{kg}$, then the overall cost will be reduced from 4.06 to $1.06 \$ / \mathrm{kg}$, a $74 \%$ reduction. Thus, if both parameters can be improved such that the overall cost is lower than 3.98 $\$ / \mathrm{kg}$, then Ext becomes a cheaper option than Atpe, assuming the base case parameters for Atpe (see Fig. 6). Also, note that the change in partition coefficient usually does not have a significant impact on the Ext cost when compared with the solvent cost and solubility (see Additional file 1: Figure S.B2). Therefore, targeting solvents with low water solubility and cost, even if the partition coefficients are low, can help reduce cost because less solvent will be lost.

Dst parameter- relative volatility For Dst1, we vary the volatility of water relative to the product from 1.1 to 3 , and the result is shown in Fig. 8c, where the cost ranges from 4.34 to $20.35 \$ / \mathrm{kg}$. Thus, even if relative volatility of 3 can be achieved, direct Dst is still more expensive than Atpe or Ext, assuming their base case parameters.

Product titer We vary the product titer from 1 to $250 \mathrm{~g} / \mathrm{L}$. As a result, the costs and the corresponding optimal technology selection are obtained and presented in Fig. 9. We 


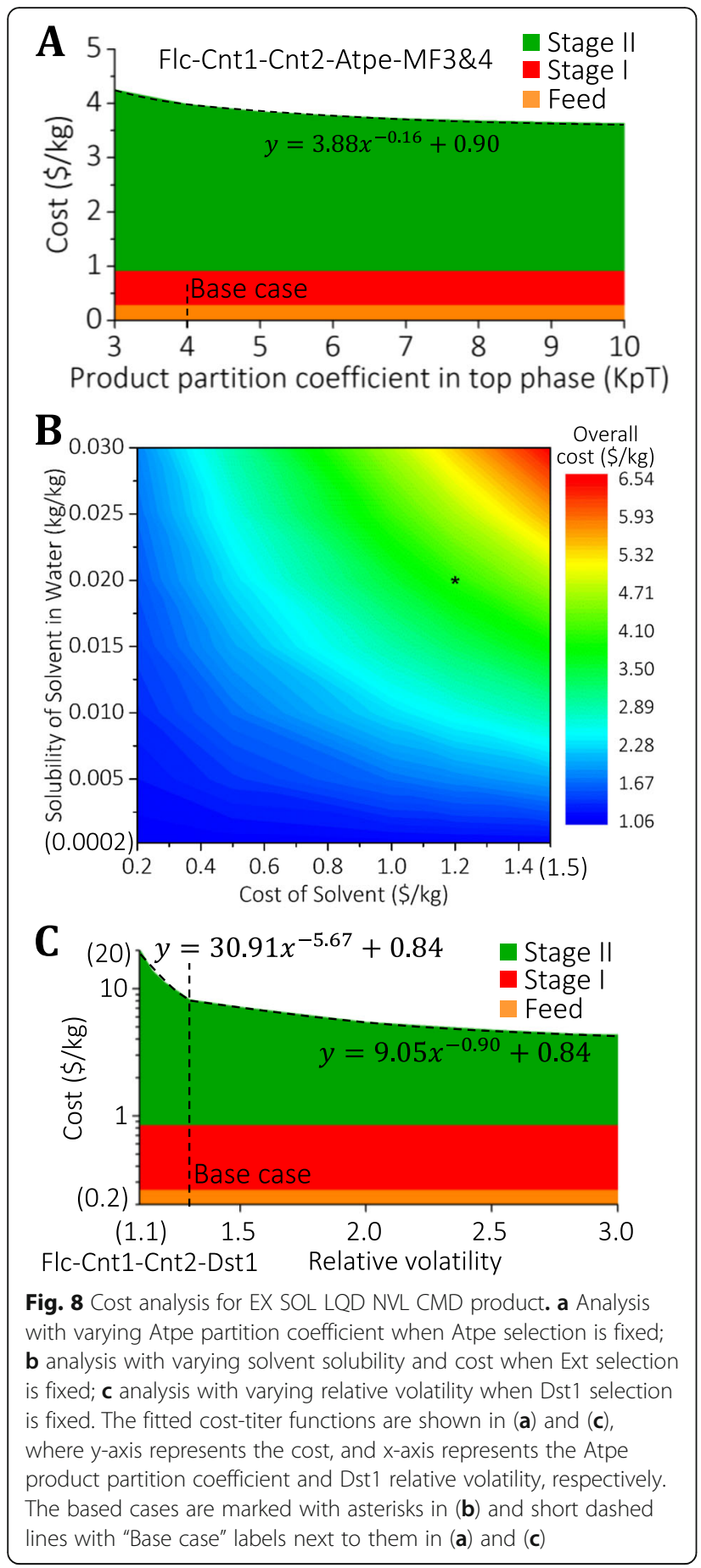

observe that when the titer is greater than $7.5 \mathrm{~g} / \mathrm{L}$, Ext selection is optimal; otherwise, Atpe selection is optimal.

\section{Extension to other classes of EX SOL products}

The other properties determining the superstructure for EX SOL products are physical state (LQD/SLD), volatility (VOL/NVL), and intended use (CMD/SPC) (see Fig. 1b).

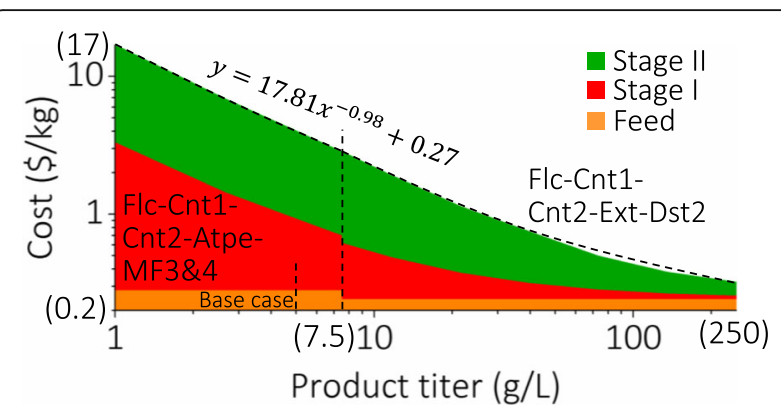

Fig. 9 Analysis with varying product titer for EX SOL LQD NVL CMD product. The fitted cost-titer functions are shown, where $y$-axis represents the cost, and $\mathrm{x}$-axis represents the product titer

For a SLD product (such as a soluble salt), Mbr and Prc can be used for product concentration as an alternative to Dst, Atpe, and Ext in Stage II. Also, in Stage III, Ads (adsorption), Crs (crystallization) and Dry (drying) can be considered. However, the cost will not likely be influenced because the desired product purity is already achieved without Stage III in the base case.

For a volatile (VOL) product, the product will be obtained at the top instead of at the bottom in Dst. Also, direct Dst is typically cheaper than Ext or Atpe when the relative volatility is greater than $1.05[51,113]$. For a specialty (SPC) product, the same argument about additional purification and stringent requirements in Stage III technologies will be valid due to high purity requirements.

\section{Conclusions}

This work focuses on the synthesis and analysis of separation processes for extracellular (EX) chemicals generated from microbial bioconversions. We first categorized EX products into (1) NSL LT, (2) NSL HV, and (3) SOL based on their physical properties. For each category, we presented a representative base case, for which a superstructure was generated, modeled and solved to identify the cost-minimal process and key cost drivers. Next, we analyzed the influence of key parameters on technology selection and cost, which is depicted in the form of sensitivity curves and heat maps. Finally, we extended the discussion to account for other classes of products in the category.

For NSL LT products, the overall cost (including feedstock cost and separation cost) of the base case $(5 \mathrm{~g} / \mathrm{L}$ product titer) is $0.65 \$ / \mathrm{kg}$. Out of the separation cost of $0.26 \$ / \mathrm{kg}$, Stage I (phase isolation) accounts for $96 \%$, and Stage II (concentration) accounts for $4 \%$. Cnt efficiency and product titer are identified to be the major influencers for technology selection and cost. Cnt is the preferred option in most cases.

For NSL HV products, the base case cost is $4.20 \mathrm{\$} / \mathrm{kg}$. Out of the separation cost of $3.81 \$ / \mathrm{kg}$, Stage I accounts for $56 \%$, and Stage III (refinement) accounts for $44 \%$. 
The required amount of Ddg agent and Slb solvent, Cnt efficiency, Ftt retention factor, and product titer are identified to be the major influencers for technology selection and cost. Ddg and Cnt are the preferred options in most cases.

For SOL products, the base case cost is $3.98 \$ / \mathrm{kg}$. Out of the separation cost of $3.7 \$ / \mathrm{kg}$, Stage I accounts for $17 \%$, and Stage II accounts for $83 \%$. Atpe partition coefficient, Ext solvent solubility and cost, Dst relative volatility, and product titer are identified to be the major influencers for technology selection and cost. Atpe or Ext is the preferred option in most cases.

In comparison, a NSL LT product has the lowest separation cost because it floats to the top and is thus naturally separated from the microbial cells settling to the bottom. Also, concentrating an NSL product is easier than concentrating a SOL product.

In this work, we have included most of the common technologies to generate reliable insights. However, new technologies can be incorporated by changing model parameters and/or adding new constraints for the corresponding technologies. The insights from the base case results, as well as the predictions associated with the varying model parameters, provide important guidance on the selection of economically promising chemicals generated from microbial conversions [114], and on the design of cost efficient separation processes. Some insights regarding future research directions for technology enhancement as well as product titer improvements are also provided for low cost production of bio-based chemicals.

\section{Supplementary information}

Supplementary information accompanies this paper at https://doi.org/10. 1186/s42480-019-0022-8

Additional file 1. Additional file for Extracellular Chemicals from Microbial Conversions.

\section{Abbreviations \\ Product properties \\ EX: extracellular; NSL: insoluble; SOL: soluble; HV: heavy; LT: light; SLD: solid; LQD: liquid; VOL: volatile (more volatile that water); NVL: non-volatile (less volatile than water); CMD: commodity; SPC: specialty}

\section{Separation technologies}

Ads: adsorption; Atpe: aqueous two phase extraction; Blc: bleaching: Byp: bypass; Chr: chromatography; Cnt: centrifugation; Crs: crystallization; Ddg: differential digestion; Dry: drying; Dst: distillation; Evp: evaporation; Ext: extraction; Flc: flocculation; Flt: flotation; Ftt: filtration; Mbr: membrane; MF: microfiltration; Prc: precipitation; Pvp: pervaporation; RO: reverse osmosis; Sdm: sedimentation; SIb: solubilization; UF: ultrafiltration

\section{Others}

MINLP: mixed integer non-linear programming; NPCM: non-product cellular materials; KpT: product partition coefficient in top phase for Atpe technology; Kp: product partition coefficient in solvent phase for Ext technology

\section{Acknowledgements}

Not applicable.

\section{Authors' contributions}

WW developed the EX NSL LT case study and contributed in writing the manuscript. KMY developed the EX NSL HV and EX SOL case studies and contributed in writing the manuscript. CTM supervised the work and writing, and provided research direction, resources, and support for performing the study. All authors read and approved the final manuscript.

\section{Funding}

This work was funded by the DOE Great Lakes Bioenergy Research Center (DOE BER Office of Science DE-SC0018409).

\section{Availability of data and materials}

Additional Supporting Information such as data, technology information and additional results may be found online in the Additional File tab for this article.

Ethics approval and consent to participate

Not applicable.

\section{Consent for publication}

Not applicable.

\section{Competing interests}

The authors declare that they have no competing interests.

Received: 21 May 2019 Accepted: 15 October 2019

Published online: 28 October 2019

\section{References}

1. Bordbar A, Monk JM, King ZA, Palsson BO. Constraint-based models predict metabolic and associated cellular functions. Nat Rev Genet. 2014;15:107-20.

2. Borodina I, Kildegaard KR, Jensen NB, Blicher TH, Maury J, Sherstyk S, et al. Establishing a synthetic pathway for high-level production of 3hydroxypropionic acid in Saccharomyces cerevisiae via $\beta$-alanine. Metab Eng. 2015;27:57-64.

3. Jullesson D, David F, Pfleger B, Nielsen J. Impact of synthetic biology and metabolic engineering on industrial production of fine chemicals. Biotechnol Adv. 2015:33:1395-402.

4. Hong K-K, Nielsen J. Metabolic engineering of Saccharomyces cerevisiae: key cell factory platform for future biorefineries. Cell Mol Life Sci. 2012;69: 2671-90.

5. Stephanopoulos G, Aristidou AA, Nielsen J. Metabolic Engineering: Principles and Methodologies. New York: Academic Press; 1998.

6. Yadav VG, De Mey M, Giaw Lim C, Kumaran Ajikumar P, Stephanopoulos G. The future of metabolic engineering and synthetic biology: towards a systematic practice. Metab Eng. 2012;14:233-41.

7. Woolston BM, Edgar S, Stephanopoulos G. Metabolic engineering: past and future. Ann Rev Chem Biomol Eng. 2013:4:259-88.

8. Wilson SA, Roberts SC. Metabolic engineering approaches for production of biochemicals in food and medicinal plants. Curr Opin Biotechnol. 2014;26: 174-82

9. Bornscheuer UT, Nielsen AT. Editorial overview: chemical biotechnology: interdisciplinary concepts for modern biotechnological production of biochemicals and biofuels. Curr Opin Biotechnol. 2015:35:133-4.

10. Kiss AA, Grievink J, Rito-Palomares M. A systems engineering perspective on process integration in industrial biotechnology. J Chem Technol Biotechnol. 2015;90:349-55

11. Herwig C, von Stockar U. A small metabolic flux model to identify transient metabolic regulations in Saccharomyces cerevisiae. Bioprocess Biosyst Eng. 2002;24:395-403.

12. Sagmeister $P$, Wechselberger $P$, Jazini M, Meitz A, Langemann T, Herwig C Soft sensor assisted dynamic bioprocess control: efficient tools for bioprocess development. Chem Eng Sci. 2013:96:190-8.

13. Barrett CL, Kim TY, Kim HU, Palsson BØ, Lee SY. Systems biology as a foundation for genome-scale synthetic biology. Curr Opin Biotechnol. 2006; 17:488-92. 
14. Marschall L, Sagmeister $P$, Herwig C. Tunable recombinant protein expression in E. coli: enabler for continuous processing? Appl Microbiol Biotechnol. 2016;100:5719-28.

15. Sato RA, da Costa MHB. Bioprocess design: study of a case. Biotechnol Lett. 1996;18:275-80

16. Asenjo JA. Bioreactor system design. Bosa Roca: CRC Press; 1994.

17. Brennan $L$, Owende P. Biofuels from microalgae - a review of technologies for production, processing, and extractions of biofuels and co-products. Renew Sust Energ Rev. 2010;14:557-77.

18. Brandt K, Schembecker G. Production rate-dependent key performance indicators for a systematic design of biochemical downstream processes. Chem Eng Technol. 2016;39:354-64.

19. Backhaus K, Lochmüller M, Arndt MC, Riechert O, Schembecker G. Knowledge-based conceptual synthesis of industrial-scale downstream processes for biochemical products. Chem Eng Technol. 2015;38:537-46.

20. Yeomans H, Grossmann IE. A systematic modeling framework of superstructure optimization in process synthesis. Comput Chem Eng. 1999; 23:709-31

21. Biegler LT, Grossmann IE, Westerberg AW. Systematic methods of chemical process design. Upper Saddle River: Prentice Hall PTR; 1997.

22. Lienqueo ME, Asenjo JA. Use of expert systems for the synthesis of downstream protein processes. Comput Chem Eng. 2000;24:2339-50.

23. Lightfoot EN, Moscariello JS. Bioseparations. Biotechnol Bioeng. 2004;87: 259-73

24. Polykarpou EM, Dalby PA, Papageorgiou LG. Optimal synthesis of chromatographic trains for downstream protein processing. Biotechnol Prog. 2011;27:1653-60

25. Simeonidis E, Pinto JM, Lienqueo ME, Tsoka S, Papageorgiou LG. MINLP models for the synthesis of optimal peptide tags and downstream protein processing. Biotechnol Prog. 2005;21:875-84

26. Vásquez-Alvarez E, Lienqueo ME, Pinto JM. Optimal synthesis of protein purification processes. Biotechnol Prog. 2001;17:685-96.

27. Sandoval G, Espinoza D, Figueroa N, Asenjo JA. Optimization of a biotechnological multiproduct batch plant design for the manufacture of four different products: a real case scenario. Biotechnol Bioeng. 2017;114:1252-63.

28. Barnicki SD, Siirola JJ. Process synthesis prospective. Comput Chem Eng. 2004:28:441-6.

29. Grossmann IE, Daichendt MM. New trends in optimization-based approaches to process synthesis. Comput Chem Eng. 1996;20:665-83.

30. Cremaschi S. A perspective on process synthesis: challenges and prospects. Comput Chem Eng. 2015;81:130-7.

31. Belter PA, Cussler EL, Hu W-S. Bioseparations: downstream processing for biotechnology. USA: Wiley; 1988.

32. Harrison RG, Todd P, Rudge SR, Petrides DP. Bioseparations Science and Engineering. Oxford: Oxford University Press; 2003.

33. Kokossis AC, Tsakalova M, Pyrgakis K. Design of integrated biorefineries. Comput Chem Eng. 2015;81:40-56.

34. Linninger AA. Industry-wide energy saving by complex separation networks. Comput Chem Eng. 2009;33:2018-27.

35. Natali JM, Pinto JM, Papageorgiou LG. Efficient MILP formulations for the simultaneous optimal peptide tag design and downstream processing synthesis. AICHE J. 2009;55:2303-17.

36. Ruiz GJ, Kim SB, Moon J, Zhang L, Linninger AA. Design and optimization of energy efficient complex separation networks. Comput Chem Eng. 2010;34: 1556-63.

37. Zhang L, Linninger AA. Towards computer-aided separation synthesis. AICHE J. 2006:52:1392-409.

38. Ponce-Ortega JM, Hortua AC, El-Halwagi M, Jiménez-Gutiérrez A. A property-based optimization of direct recycle networks and wastewater treatment processes. AICHE J. 2009;55:2329-44

39. Steffens MA, Fraga ES, Bogle ID. Synthesis of bioprocesses using physical properties data. Biotechnol Bioeng. 2000:68:218-30.

40. Steffens MA, Fraga ES, Bogle IDL. Multicriteria process synthesis for generating sustainable and economic bioprocesses. Comput Chem Eng. 1999:23:1455-67.

41. Dowling AW, Biegler LT. A framework for efficient large scale equationoriented flowsheet optimization. Comput Chem Eng. 2015;72:3-20.

42. Wu W, Yenkie KM, Maravelias CT. A superstructure-based framework for bioseparation network synthesis. Comput Chem Eng. 2017;96:1-17.

43. Kim J, Sen SM, Maravelias CT. An optimization-based assessment framework for biomass-to-fuel conversion strategies. Energy Environ Sci. 2013;6:1093.
44. Rizwan M, Lee JH, Gani R. Optimal processing pathway for the production of biodiesel from microalgal biomass: a superstructure based approach Comput Chem Eng. 2013;58:305-14.

45. Jiménez-González C, Woodley JM. Bioprocesses: modeling needs for process evaluation and sustainability assessment. Comput Chem Eng. 2010;34:1009-17.

46. Heinzle E, Biwer AP, Cooney CL. Development of Bioprocesses. Development of Sustainable Bioprocesses. NJ: Wiley; 2007. p. 11-59.

47. González-Delgado Á-D, Kafarov V, El-Halwagi M. Development of a topology of microalgae-based biorefinery: process synthesis and optimization using a combined forward-backward screening and superstructure approach. Clean Techn Environ Policy. 2015;17:2213-28.

48. Kokossis AC, Yang A, Tsakalova M, Lin T-C. A systems platform for the optimal synthesis of biomass based manufacturing systems. In: Pierucci S, Ferraris GB, editors. Computer Aided Chemical Engineering. Naples: Elsevier; 2010. p. 11051110

49. Schaber SD, Gerogiorgis DI, Ramachandran R, Evans JMB, Barton PI, Trout $\mathrm{BL}$. Economic analysis of integrated continuous and batch pharmaceutical manufacturing: a case study. Ind Eng Chem Res. 2011;50:10083-92.

50. Yenkie KM, Wu W, Clark RL, Pfleger BF, Root TW, Maravelias CT. A roadmap for the synthesis of separation networks for the recovery of bio-based chemicals: matching biological and process feasibility. Biotechnol Adv. 2016; 34:1362-83.

51. Yenkie KM, Wu W, Maravelias CT. Synthesis and analysis of separation networks for the recovery of intracellular chemicals generated from microbial-based conversions. Biotechnol Biofuels. 2017:10:119.

52. Jones CM, Lozada NJH, Pfleger BF. Efflux systems in bacteria and their metabolic engineering applications. Appl Microbiol Biotechnol. 2015;99: 9381-93.

53. Rangaswamy $\vee$, Jain $D$. An efficient process for production and purification of hyaluronic acid from Streptococcus. Biotechnol Lett. 2007;30:493-6.

54. Liu L, Liu Y, Li J, Du G, Chen J. Microbial production of hyaluronic acid: current state, challenges, and perspectives. Microb Cell Factories. 2011;10:99.

55. Reddy KJ, Karunakaran KT. Purification and characterization of hyaluronic acid produced by Streptococcus zooepidemicus strain 3523-7. J Biosci Biotechnol. 2013:2:173-9.

56. Widner B, Behr R, Von Dollen S, Tang M, Heu T, Sloma A, et al. Hyaluronic acid production in Bacillus subtilis. Appl Environ Microbiol. 2005;71:3747-52.

57. Bracke JW, Thacker K. Hyaluronic acid from bacterial culture. 1985. Available from: http://www.google.com/patents/US4517295. [cited 2016 Mar 25]

58. Kiyota H, Okuda Y, Ito M, Hirai MY, Ikeuchi M. Engineering of cyanobacteria for the photosynthetic production of limonene from CO2. J Biotechnol. 2014;185:1-7.

59. Jongedijk E, Cankar K, Ranzijn J, van der Krol S, Bouwmeester H, Beekwilder J. Capturing of the monoterpene olefin limonene produced in Saccharomyces cerevisiae. Yeast. 2015;32:159-71.

60. Pourbafrani M, Forgács G, Horváth IS, Niklasson C, Taherzadeh MJ. Production of biofuels, limonene and pectin from citrus wastes. Bioresour Technol. 2010;101:4246-50.

61. Davies FK, Work VH, Beliaev AS, Posewitz MC. Engineering limonene and Bisabolene production in wild type and a glycogen-deficient mutant of Synechococcus sp. PCC 7002. Front Bioeng Biotechnol. 2014;2(21):1-11.

62. García-Ochoa F, Santos VE, Casas JA, Gómez E. Xanthan gum: production, recovery, and properties. Biotechnol Adv. 2000;18:549-79.

63. Rosalam S, England R. Review of xanthan gum production from unmodified starches by Xanthomonas comprestris sp. Enzym Microb Technol. 2006;39: 197-207.

64. Afschar AS, Vaz Rossell CE, Jonas R, Quesada Chanto A, Schaller K. Microbial production and downstream processing of 2,3-butanediol. J Biotechnol. 1993:27:317-29.

65. Anvari M, Pahlavanzadeh H, Vasheghani-Farahani E, Khayati G. In situ recovery of 2,3-butanediol from fermentation by liquid-liquid extraction. J Ind Microbiol Biotechnol. 2009;36:313-7.

66. Birajdar SD, Padmanabhan S, Rajagopalan S. Repulsive effect of salt on solvent extraction of 2,3-butanediol from aqueous fermentation solution. J Chem Technol Biotechnol. 2015;90:1455-62.

67. Celińska E, Grajek W. Biotechnological production of 2,3butanediol_current state and prospects. Biotechnol Adv. 2009:27:715-25.

68. Abdel-Rahman MA, Tashiro Y, Sonomoto K. Recent advances in lactic acid production by microbial fermentation processes. Biotechnol Adv. 2013;31: 877-902. 
69. Bishai M, De S, Adhikari B, Banerjee R. A platform technology of recovery of lactic acid from a fermentation broth of novel substrate Zizyphus oenophlia. 3 Biotech. 2015;5:455-63.

70. Ghaffar T, Irshad M, Anwar Z, Aqil T, Zulifqar Z, Tariq A, et al. Recent trends in lactic acid biotechnology: a brief review on production to purification. $J$ Radiat Res Appl Sci. 2014;7:222-9.

71. Li Y, Shahbazi A, Williams K, Wan C. Separate and concentrate lactic acid using combination of nanofiltration and reverse osmosis membranes. Appl Biochem Biotechnol. 2008;147:1-9.

72. Okano K, Tanaka T, Kondo A. Lactic Acid. Bioprocessing of Renewable Resources to Commodity Bioproducts. NJ: Wiley; 2014. p. 353-380. Available from: https://onlinelibrary.wiley.com/doi/abs/10.1002/9781118845394.ch13.

73. Benavides J, Ritopalomares M. Simplified two-stage method to Bphycoerythrin recovery from Porphyridium cruentum $\{$. J Chromatogr B. 2006;844:39-44.

74. Mujtaba IM. Application of neural networks and other learning Technologies in Process Engineering. London: World Scientific; 2001

75. Polykarpou EM, Dalby PA, Papageorgiou LG. A novel efficient optimisation system for purification process synthesis. Biochem Eng J. 2012;67:186-93.

76. Schenk M, Gani R, Bogle D, Pistikopoulos EN. A hybrid Modelling approach for separation systems involving distillation. Chem Eng Res Des. 1999;77:519-34.

77. Winkelnkemper T, Schembecker G. Purification performance index and separation cost indicator for experimentally based systematic downstream process development. Sep Purif Technol. 2010;72:34-9.

78. Chhatre S, Francis R, Newcombe AR, Zhou Y, Titchener-Hooker N, King J, et al. Global sensitivity analysis for the determination of parameter importance in bio-manufacturing processes. Biotechnol Appl Biochem. 2008:51:79-90.

79. Zhang Y, Dubé MA, McLean DD, Kates M. Biodiesel production from waste cooking oil: 2. Economic assessment and sensitivity analysis. Bioresour Technol. 2003;90:229-40

80. Harrison RG. Bioseparation Basics. Chemical Engineering Progress. 2014; Available from: http://www.aiche.org/resources/publications/cep/2014/ october/bioseparation-basics. [cited 2016 Jun 14]

81. Molina Grima E, Belarbi E-H, Acién Fernández FG, Robles Medina A, Chisti Y. Recovery of microalgal biomass and metabolites: process options and economics. Biotechnol Adv. 2003;20:491-515.

82. Banerjee A, Sharma R, Chisti Y, Banerjee UC. Botryococcus braunii: a renewable source of hydrocarbons and other chemicals. Crit Rev Biotechnol. 2002;22:245-79.

83. Grothe $E$, Moo-Young M, Chisti Y. Fermentation optimization for the production of poly( $\beta$-hydroxybutyric acid) microbial thermoplastic. Enzym Microb Technol. 1999;25:132-41.

84. Sharma R, Chisti Y, Banerjee UC. Production, purification, characterization, and applications of lipases. Biotechnol Adv. 2001;19:627-62.

85. Chisti Y. Strategies in Downstream Processing. In: Subramanian G, editor. Bioseparation and Bioprocessing: Wiley-VCH Verlag GmbH; 1998. p. 1-30. Available from: http://onlinelibrary.wiley.com/doi/10.1002/9783527619641. ch18/summary. [cited 2016 Apr 5].

86. Asenjo JA. Separation processes in biotechnology. New York: Marcel Dekker Inc.; 1990.

87. Asenjo JA, Andrews BA. Challenges and trends in bioseparations. J Chem Technol Biotechnol. 2008:83:117-20.

88. Steffens MA, Fraga ES, Bogle IDL. Synthesis of purification tags for optimal downstream processing. Comput Chem Eng. 2000;24:717-20.

89. Agena SM, Bogle IDL, Cornish ARH. Process synthesis for particle separations using centrifuges. Comput Chem Eng. 1998;22:351-6.

90. Ho W, Sirkar K. Membrane Handbook. New YorkUSA: Springer; 1992.

91. Shao J, Zydney AL. Optimization of ultrafiltration/diafiltration processes for partially bound impurities. Biotechnol Bioeng. 2004;87:286-92.

92. van Reis R, Zydney A. Bioprocess membrane technology. J Membr Sci. 2007; 297:16-50.

93. Ulrich GD, Vasudevan PT. Chemical Engineering Process Design and Economics: A Practical Guide. Bosa Roca: Process Pub; 2004.

94. Kılınç MR, Sahinidis NV. Exploiting integrality in the global optimization of mixed-integer nonlinear programming problems with BARON. Optimization Methods Softw. 2018;33:540-62.

95. Tawarmalani M, Sahinidis NV. A polyhedral branch-and-cut approach to global optimization. Math Program. 2005;103:225-49.

96. Wu W, Maravelias $\subset$. Synthesis and techno-economic assessment of microbialbased processes for terpenes production. Biotechnol Biofuels. 2018;11:294.
97. Zhou YJ, Gao W, Rong Q, Jin G, Chu H, Liu W, et al. Modular pathway engineering of Diterpenoid synthases and the Mevalonic acid pathway for Miltiradiene production. J Am Chem Soc. 2012;134:3234-41.

98. Chandran SS, Kealey JT, Reeves CD. Microbial production of isoprenoids. Process Biochem. 2011;46:1703-10.

99. Ajikumar PK, Tyo K, Carlsen S, Mucha O, Phon TH, Stephanopoulos G. Terpenoids: opportunities for biosynthesis of natural product drugs using engineered microorganisms. Mol Pharm. 2008:5:167-90.

100. Ambler CM. The fundamentals of separation, including Sharples "sigma value" for predicting equipment performance. Ind Eng Chem Res. 1961;53: 430-3.

101. Kennedy JF, Cabral JMS. Recovery processes for biological materials. 1 edition. Chichester England. New York: Wiley; 1993.

102. Aikawa S, Nishida A, Ho S-H, Chang J-S, Hasunuma T, Kondo A. Glycogen production for biofuels by the euryhaline cyanobacteria Synechococcus sp. strain PCC 7002 from an oceanic environment. Biotechnol Biofuels. 2014;7:88.

103. Castanha RF, de Morais LAS, Mariano AP, Monteiro RTR. Comparison of two lipid extraction methods produced by yeast in cheese whey. Braz Arch Biol Technol. 2013;56:629-36.

104. Lee SU, Jung K, Park GW, Seo C, Hong YK, Hong WH, et al. Bioprocessing aspects of fuels and chemicals from biomass. Korean J Chem Eng. 2012;29: 831-50.

105. Li Q, Du W, Liu D. Perspectives of microbial oils for biodiesel production. Appl Microbiol Biotechnol. 2008;80:749-56.

106. Kontoravdi C, Samsatli NJ, Shah N. Development and design of biopharmaceutical processes. Curr Opin Chem Eng. 2013;2:435-41.

107. Sun Y, Ma C, Fu H, Mu Y, Xiu Z. 1,3-Propanediol. In: Bisaria VS, Kondo A, editors. Bioprocessing of Renewable Resources to Commodity Bioproducts: Wiley; 2014. p. 289-326. Available from: http://onlinelibrary.wiley.com/doi/1 0.1002/9781118845394.ch11/summary. [cited 2015 Oct 16].

108. Xiu Z-L, Zeng A-P. Present state and perspective of downstream processing of biologically produced 1,3-propanediol and 2,3-butanediol. Appl Microbiol Biotechnol. 2008:78:917-26.

109. Jiang B, Li Z-G, Dai J-Y, Zhang D-J, Xiu Z-L. Aqueous two-phase extraction of 2,3-butanediol from fermentation broths using an ethanol/phosphate system. Process Biochem. 2009;44:112-7.

110. Benavides J, Rito-Palomares M, Asenjo JA. Aqueous two-phase systems. In Moo-Young M, editor. Comprehensive biotechnology. 2nd ed. Burlington: Academic Press; 2011. p. 697-713. Available from: http://www.sciencedirect. com/science/article/pii/B9780080885049001240.

111. Hatti-Kaul R. Aqueous two-phase systems. Mol Biotechnol. 2001;19:269-77.

112. Mistry SL, Asenjo JA, Zaror CA. Mathematical modelling and simulation of aqueous two-phase continuous protein extraction. Bioseparation. 1992;3:343-58.

113. Towler G, Sinnott RK. Chemical engineering design, second edition: principles, practice and economics of plant and process design. 2nd ed. Boston: Butterworth-Heinemann; 2012.

114. Wu W, Long MR, Zhang X, Reed JL, Maravelias CT. A framework for the identification of promising bio-based chemicals. Biotechnol Bioeng. 2018. 115:2328-40.

\section{Publisher's Note}

Springer Nature remains neutral with regard to jurisdictional claims in published maps and institutional affiliations.

Ready to submit your research? Choose BMC and benefit from

- fast, convenient online submission

- thorough peer review by experienced researchers in your field

- rapid publication on acceptance

- support for research data, including large and complex data types

- gold Open Access which fosters wider collaboration and increased citations

- maximum visibility for your research: over $100 \mathrm{M}$ website views per year

At BMC, research is always in progress.

Learn more biomedcentral.com/submission 